\title{
Marital communication skills training to promote marital satisfaction and psychological health during pregnancy: a couple focused approach
}

\author{
Zahra Alipour', Ashraf Kazemi ${ }^{2 *}$ (D, Gholamreza Kheirabadi ${ }^{3}$ and Ahmad-Ali Eslami ${ }^{4}$
}

\begin{abstract}
Background: Studies showed that decreased marital satisfaction and increased risk of depression and anxiety were mutually related. Therefore, this study was conducted to evaluate the effect of communication skills training with a couple focused approach on marital satisfaction and psychological symptoms among pregnant women.

Methods: This experimental study was performed on 60 pregnant women with low marital satisfaction who were divided into two groups of intervention and control. The women in the intervention group and their husbands participated in a communication training program based on the couple focused approach. The levels of anxiety, depression, and marital satisfaction were evaluated before and then one and three months after the intervention using valid questionnaires.
\end{abstract}

Results: The results indicated that after the intervention, compared to the pre-intervention period, the levels of marital satisfaction increased while the levels of depression and anxiety decreased significantly in the intervention group $(p<0.05)$. The comparison of the groups revealed significant differences in the scores of marital satisfaction, depression, and anxiety in the intervention and control groups at the intervals of one month and three months after the intervention $(p<0.05)$.

Conclusions: The research findings indicated that communication skills training program based on the couple focused approach and an emphasis on the needs of pregnant women during the pregnancy can improve the marital satisfaction and psychological health of pregnant women.

Trial registration: Iranian Registry of Clinical Trials IRCT2017012932264N2, Date of registration: 2017-06-28 Retrospectively registered.

Keywords: Anxiety, Depression, Marital satisfaction, Pregnancy, Communication, Couple focused approach

\section{Plain English summery}

Low marital satisfaction and risk of depression and anxiety were mutually related. Therefore, this study was conducted to evaluate the effect of communication skills training with a couple focused approach on marital satisfaction and psychological symptoms among pregnant women. This experimental study was performed on 60 pregnant women with low marital satisfaction. The

\footnotetext{
* Correspondence: Kazemi@nm.mui.ac.ir

${ }^{2}$ Nursing and Midwifery Care Research Center, School Of Nursing and Midwifery, Isfahan University of Medical Sciences, Hezarjerib AV, Isfahan, Iran Full list of author information is available at the end of the article
}

women in the intervention group and their husbands participated in a communication training program. The levels of anxiety, depression and marital satisfaction were evaluated before, then one month and three months after the intervention using valid questionnaires. The results indicated that after the intervention, compared to the pre-intervention period, the levels of marital satisfaction increased, while the levels of depression and anxiety decreased significantly in the intervention group. The comparison of the groups revealed significant differences in the scores of marital satisfaction, depression, and anxiety in the intervention and control groups at the intervals of 
one month and three months after the intervention. The research findings indicated that communication skills training program can improve the marital satisfaction and psychological health of pregnant women.

\section{Background}

Physical and psychological changes in women during pregnancy and the transition to the parenthood period pose new challenges and may be followed by poor relationship between the spouses and may reduce the quality of marital relationship [1, 2]. These circumstances can lead to development of psychological disorders in pregnant women, including depression and anxiety [3]. These disorders may have some negative impacts on the outcome of pregnancy. The existing evidence shows that pregnancy depression is associated with an increased risk of preeclampsia and preterm labor as well as low birth weight [4-6]. In addition, the use of Selective Serotonin Reuptake Inhibitors, which is useful in the treatment of pregnancy depression, has recently been reported to increase fetal complications including low birth weight and decreased neonatal Apgar score [7].

Furthermore, antenatal psychological disorders are associated with an increased likelihood of postpartum depression [8]. There is also evidence showing that pregnancy depression and anxiety can decrease the quality of motherinfant communication [9]. Therefore, efforts for modifying the factors that can improve women's mental health are important in ensuring maternal and child health.

Previous studies showed that a psychological intervention for eliminating anxiety and fear in pregnant women caused by interventional prenatal diagnosis was effective [10]; however, based on the results of some systematic reviews, these studies were not sufficient for giving verdict on the impact of psychological interventions on mental health in women with vulnerable pregnancies [11, 12]. In order to maintain and improve the mental health of pregnant women, we need to increase the ability of couples to resolve their conflicts, after formation of new relationships between partners due to the physical and emotional changes during pregnancy. Evidence suggests that acquiring communication skills can improve the quality of marital relationships and reduce psychological disorders such as depression and anxiety [13].

Factors affecting the psychological health of pregnant women have a great deal of diversity and complexities, and communication skills training may be associated with different results compared to other periods of life. Accordingly, this study was performed to assess the impact of communication skills training on marital satisfaction and levels of depression and anxiety in pregnant women by focusing on the emotional-psychological needs of women during pregnancy.

\section{Methods}

This randomized controlled field trial was conducted with the approval of the Ethics Committee of Isfahan University of Medical Sciences on pregnant women in prenatal care from August 2017 to January 2018 in Isfahan, Iran. The study inclusion criteria were a gestational age less than 24 weeks, the absence of systemic diseases, not taking antidepressants and anti-anxiety drugs, lack of polygyny, and low levels of marital satisfaction. The sample size was considered as 30 subjects for case and control groups with $95 \%$ confidence level and test power of $80 \%$. The samples were selected from those referred to Isfahan health centers after obtaining informed consent.

The health centers were selected by random clustering method. Health services in Isfahan are organized by two health care networks. Therefore, two networks were considered as clusters and four health care centers covered by each network were selected randomly. Pregnant women who underwent prenatal care in the health care centers were selected through convenience sampling.

Initially, 169 pregnant women were enrolled in the study and completed the ENRICH marital satisfaction questionnaire and answered the questions related to the subscales of depression and anxiety of General Health Questionnaire (GHQ). To determine the sensitivity and specificity of marital satisfaction questionnaire and obtain the best cut-off point for marital dissatisfaction, the marital satisfaction scores were used in the agreement with the scores of anxiety and depression scales of the GHQ by applying the "Receiver Operating Characteristic Curve ROC Curve. The cut-off point of 28 was determined based on a sensitivity of $66.1 \%$ and specificity of $35.45 \%$. Thus, out of 169 participants, the marital satisfaction score of 97 women was less than 28. Among the 97 eligible women, 60 women were selected randomly and, after recording their demographic characteristics, marital satisfaction questionnaires and subscales of depression and anxiety of the GHQ were completed by them. In order to assign the participants randomly to the intervention and control groups, 60 closed envelopes were prepared containing 30 blue and 30 green cards (Fig. 1). The envelopes, together with the file number of the participants, were provided to the prenatal care givers at four centers, and they were asked to give one of the envelopes to the participant who is referred to their ward. The prenatal care providers, therefore, were blinded to the study group. The researcher, then, assigned the bluecarded couples to the intervention group and the greencarded couples to the control group.

After implementing the educational program, the marital satisfaction and levels of depression and anxiety were reevaluated one and three months after the training course.

The data were collected and subsequently analyzed in a blinded method, that is, the prenatal care providers and data analyzer were blinded to the study group. Also, each group was not aware of any other type of intervention. 


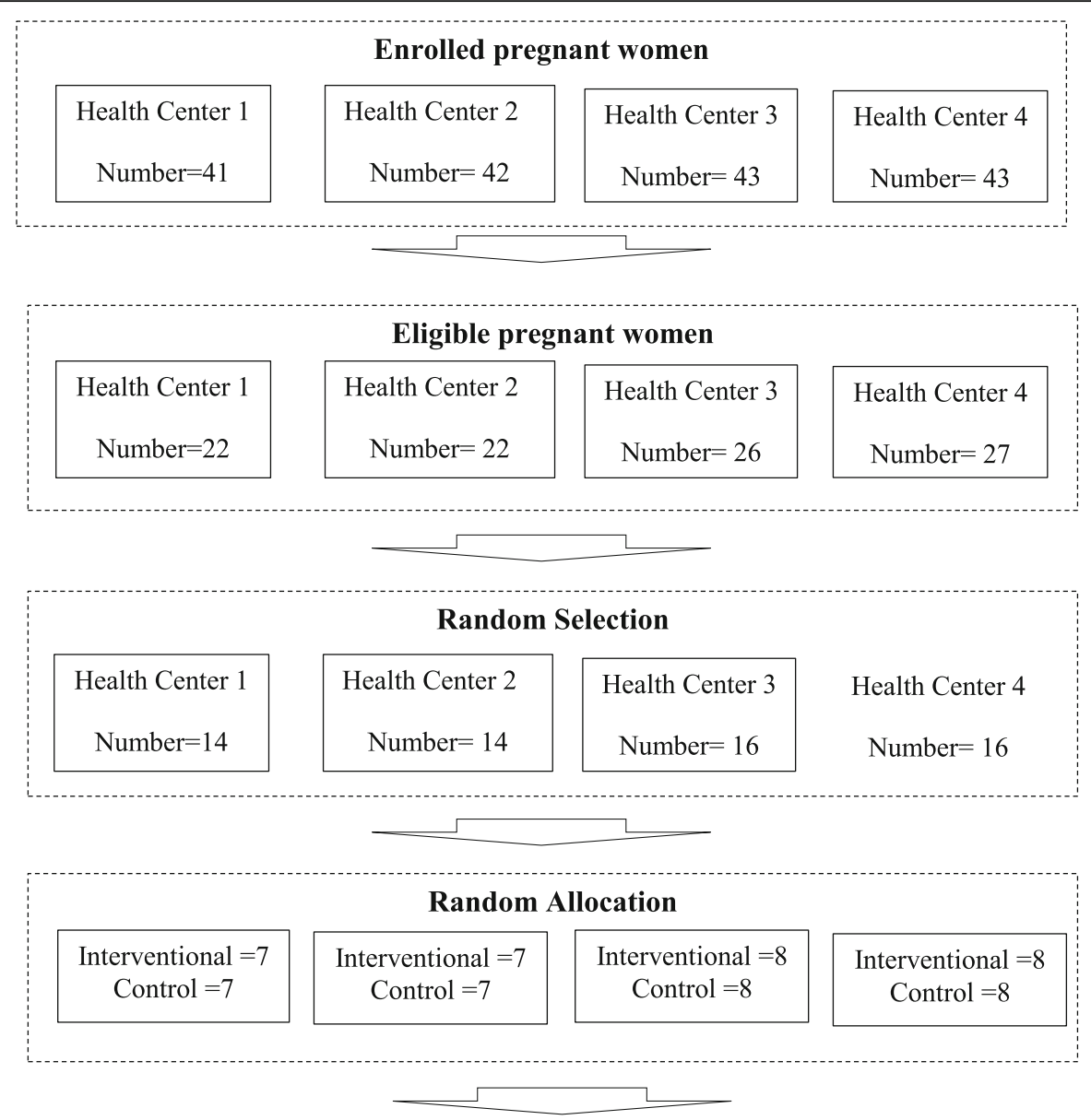

\begin{tabular}{c}
\hline Intervention Group \\
Excluded: 3 women \\
Failing to complete the questionnaires $=2$ \\
Absence in the training sessions $=1$ \\
Analysis: 27 women
\end{tabular}

Control Group
Excluded $=3$
Failing to complete the questionnaires $=3$
Analysis: 27 women

Fig. 1 Consort diagram

\section{Intervention}

The communication skills training package with the couple-based intervention was developed based on the documents [14-16] as well as the opinions of experts on psychology, psychiatry and reproductive health. For example, a psychologist believed that to improve the couple's relationship, the couples' mutual understanding of each other's feelings and conditions are necessary factor. In this regard, a reproductive health specialist recommended that psychological changes in women during pregnancy be included in the program content. Both the psychiatrist and the psychologist believed that training mindfulness skills in couples would contribute to the mutual understanding and management of their relationships.
Communication skills training program was conducted in four health centers for couples during 7 sessions. The duration of each session was $2 \mathrm{~h}$ and 2 sessions were held each week. 7 to 8 couples from each center participated in the study. The training was delivered as lectures, group discussions and role playing, under the supervision of a specialist in clinical psychology. At the beginning of each session, the skill learned in the previous session was practiced practically for half an hour.

The educational subjects of training sessions were focused on the re-establishment of appropriate communication between partners including the establishment of a good relationship and creation of an atmosphere of trust and security, understanding the changes and psychological needs of pregnant women, the importance of communication skills, 
psychological health during pregnancy, the description of the differences between men and women, common problems in the family, training of self-awareness and self-care skills, and the assessment of the communication barriers in them.

During training, the problems were described by couples, and the self-awareness strategy training was provided, to be used at an occurrence of interpersonal problems and describing the cycle of awareness and familiarity. Then the five parts of awareness cycle were practiced by the couples, including sensory information, expressing the thoughts, feelings, desires and expectations with respect to the needs and changes of pregnancy [16].

Self-awareness strategies included self-assessment, identification of the strengths and weaknesses, positive thinking, and the development of positive self-image. Activities were designed to empower couples for each of these strategies, and exercises were trained for the identification of emotions and visualization of abilities and desires, as well as awareness of individual characteristics.

During the remaining sessions, the training was focused on the effective marital relationship, barriers to effective communication, describing the types of problems in three categories of thematic problems, own or spouse's personal problems, and relational problems. Moreover, the skills of the message sender and receiver skills, effective listening skills and speaking skills, identifying factors contributing to active listening, expressing the emotions presented and six speaking skills including showing emotions, expressing demands, outlining the actions, speaking on behalf of oneself, describing the sensory information, expressing opinions with respect to changes of pregnancy were practiced by using the awareness cycle.

The contents of the sixth and seventh sessions included how to identify the conflict and the factors affecting it, couple's familiarity with effective conflict management, identifying common interests and respecting individual interests, identifying unsuccessful models of conflict resolution, training to discuss the role of unrealistic expectations in the development of conflict, effective conflict management, and teaching skills of stress and anger management. Also, the discussions were summarized to make conclusions and answer the questions. For the couples in the control group, two sessions of childbirth preparation were provided, including familiarity with the exercises during pregnancy, pregnancy and childbirth process, obstetric problems and complications and providing preventive strategies to deal with complications during pregnancy.

Since marital satisfaction was low in the intervention group and because of the moral considerations, the educational pamphlets were also given to the subjects of the control group after the completion of the third phase of the study. The importance of marital relationship improvement for promoting the mental health of the pregnant women had been explained in this pamphlet.

\section{Tools}

To measure the marital satisfaction level, the 47-question form of valid ENRICH questionnaire was used [17]. This questionnaire is designed with four domains including marital satisfaction, sexual satisfaction, conflict resolution and marital communication in a five-item Likert scale (04): strongly disagree (0), disagree (1), somehow disagree or agree (2), agree (3), and strongly agree (4). The questionnaire sum score ranged from 0 to 188 points and the higher scores indicate the higher marital satisfaction.

To measure depression and anxiety levels, the subscales of anxiety and depression of valid General Health Questionnaire [18] were used. Each of the depression and anxiety subscales consists of seven items. This tool is designed based on 4-item Likert scale (0-3): strongly disagree (0), disagree (1), agree (2), and strongly agree (4). The questionnaire sum score ranged from 0 to 21 points. The higher scores indicate the higher depression and anxiety levels.

\section{Statistical analysis}

The data obtained from the study were analyzed using SPSS 19 software and statistical methods of the independent $\mathrm{t}$-test, pair $\mathrm{t}$ test, chi-square, repeated measures analysis of variance (RMANOVA), and Pearson correlation coefficient. Also, the data normality was evaluated through the Kolmogorov-Smirnov test.

\section{Results}

Of the 60 participants of the study, 6 subjects were excluded from the study that was due to their failure in completing the questionnaires and not attending more than $30 \%$ of the training sessions in the intervention group (Fig. 1). Then, the analysis was performed on data from 54 participants with an average age of 29.5 years. The Kolmogorov test results showed that the scores of depression, anxiety, and marital satisfaction variables had a normal distribution. Comparing the background characteristics and the scores of marital satisfaction, anxiety, and depression before the intervention revealed no significant differences (Table 1). Comparison of the means scores of marital satisfaction, depression, and anxiety in three intervals of before, one month and three months after the intervention in both groups are given in Table 2. The level of depression and anxiety three month after intervention was lower $(p=.001)$ and the marital satisfaction $(p=.003)$ was higher in the intervention group than in the control group. The results showed the impact of group in the level of depression $(p=.03)$, anxiety $(p<.001)$ and marital satisfaction $(p=.004)$ were significant. Also, the results showed that during the study follow-ups in the intervention group, significant changes in the levels of anxiety, depression and marital satisfaction $(\mathrm{p}<.001)$ occurred (Table 3$)$. 
Table 1 Comparison of baseline characteristics in study groups

\begin{tabular}{|c|c|c|}
\hline & Intervention Group ( $n=27$ ) & Control Group $(n=27)$ \\
\hline & Mean (SD) or Number (\%) & Mean (SD) or Number (\%) \\
\hline Age of husband & $33.5(4.2)$ & $33.5(5.1)$ \\
\hline Age of women & $29.1(4.3)$ & $29.4(4.5)$ \\
\hline Gestational age & $18.7(6.8)$ & $21.4(4.1)$ \\
\hline Length of marriage & $4.6(3.8)$ & $5.4(4.2)$ \\
\hline \multicolumn{3}{|c|}{ Education level of husband (\%) } \\
\hline High school or less & $16(59.2)$ & $15(55.5)$ \\
\hline More than high school & $11(40.8)$ & $12(44.5)$ \\
\hline \multicolumn{3}{|l|}{ Education level of women (\%) } \\
\hline High school or less & $10(37.1)$ & $15(55.5)$ \\
\hline More than high school & $17(62.9)$ & $12(44.5)$ \\
\hline \multicolumn{3}{|c|}{ Occupational status of women (\%) } \\
\hline Employed & $4(14.8)$ & $5(18.5)$ \\
\hline \multicolumn{3}{|l|}{ Economic level (\%) } \\
\hline Low & $1(3.7)$ & $1(3.7)$ \\
\hline Medium & $19(70.4)$ & $20(74.1)$ \\
\hline High & $7(25.9)$ & $6(22.2)$ \\
\hline \multicolumn{3}{|l|}{ Parity (\%) } \\
\hline Primparity & $19(70.4)$ & $16(59.3)$ \\
\hline Multiparty & $8(29.6)$ & $11(40.7)$ \\
\hline History of abortion (\%) & $3(11.1)$ & $5(18.5)$ \\
\hline Obstetric complications (\%) & $3(11.1)$ & $2(7.4)$ \\
\hline
\end{tabular}

Abbreviations: $S D$ standard deviation, sig significance, $n s$. not significant

Table 2 Comparison of anxiety, depression, and marital satisfaction scores between two groups by three times

\begin{tabular}{|c|c|c|c|c|c|c|c|}
\hline & \multicolumn{2}{|l|}{ Mean (SD) } & \multirow[b]{2}{*}{$\mathrm{Sig}^{\mathrm{a}}$} & \multicolumn{4}{|c|}{ Time/ Group } \\
\hline & Intervention Group ( $n=27)$ & Control Group $(n=27)$ & & $\overline{F^{b}}$ & $\mathrm{Sig}^{\mathrm{b}}$ & $F^{c}$ & $\operatorname{Sig}^{c}$ \\
\hline \multicolumn{8}{|l|}{ Anxiety } \\
\hline At Intake & $8.33(4.67)$ & $7.74(4.18)$ & ns & 14.21 & $<.001$ & 4.94 & .03 \\
\hline After 1 month & $4.29(2.35)$ & $7.22(4.90)$ & .007 & & & & \\
\hline After 3 month & $3.25(2.87)$ & $6.77(3.96)$ & .001 & & & & \\
\hline \multicolumn{8}{|l|}{ Depression } \\
\hline At Intake & $2.88(2.75)$ & $4.40(5.37)$ & ns & 4.88 & .03 & 7.14 & .01 \\
\hline After 1 month & $1.66(1.86)$ & $3.14(4.07)$ & ns & & & & \\
\hline After 3 month & $0.74(1.16)$ & $3.81(4.48)$ & .001 & & & & \\
\hline \multicolumn{8}{|l|}{ Marital satisfaction } \\
\hline At Intake & $155.25(21.09)$ & $152.55(22.27)$ & ns & 9.30 & .004 & 4.93 & .04 \\
\hline After 1 month & $170.00(15.98)$ & $159.44(21.80)$ & $<.05$ & & & & \\
\hline After 3 month & 177.18 (17.33) & $160.22(23.02)$ & .003 & & & & \\
\hline
\end{tabular}

Abbreviations: $S D$ standard deviation, sig significance, $n$ s not significant

a: Results of $t$ test

b. Results of repeated measures analysis of variance (RMANOVA)

c test of within subject effect

${ }^{b}$ test of between subject effect 
Table 3 The results of pair t test for anxiety, depression, and marital satisfaction

\begin{tabular}{|c|c|c|c|c|}
\hline \multirow[b]{2}{*}{ Group } & \multirow[b]{2}{*}{ Time } & \multicolumn{3}{|l|}{ Sig } \\
\hline & & Anxiety & Depression & Marital satisfaction \\
\hline \multicolumn{5}{|c|}{ Intervention Group } \\
\hline \multirow[t]{2}{*}{ At intake } & After 1 month & $<.001$ & $<.001$ & $<.001$ \\
\hline & After 3 month & $<.001$ & .001 & $<.001$ \\
\hline After 1 month & After 3 month & .04 & .02 & .006 \\
\hline \multicolumn{5}{|l|}{ Control Group } \\
\hline \multirow[t]{2}{*}{ At intake } & After 1 month & ns & ns & .04 \\
\hline & After 3 month & ns & ns & ns \\
\hline After 1 month & After 3 month & ns & ns & ns \\
\hline
\end{tabular}

Results showed a significant inverse correlation between the level of marital satisfaction and anxiety and depression scores before, 2 and 3 months after the intervention (Table 4).

\section{Discussion}

The aim of this study was to evaluate the effect of teaching communication skills on marital satisfaction and psychological health of pregnant women with low levels of marital satisfaction. The present study indicated that the efforts made to increase women's communication skills would be associated with their improved psychological health and increased marital satisfaction. Many studies have shown that communication skill training is effective in reducing marital conflicts $[19,20]$ and improving the communication between couples [16], and improves the couples' psychological health $[13,21]$. During pregnancy, due to physical and emotional changes in women, abnormal relationships may be experienced by the couples [2]; however, this study confirmed that during pregnancy, like other periods of life, communication skills training for women can improve such communications and relationships. Meanwhile, the results of this study showed that although the effect of communication skills training on marital satisfaction was greater than the baseline up to three months after the intervention, the marital satisfaction within one to three months after the intervention did not increase, while it is expected that acquiring communication skills over time would be influenced by further impacts of improved relationships in this period. This finding suggests that efforts to improve communication skills during pregnancy require supplemental plans to stabilize the effect of the program on couple's communication skills. In addition, no increase in the marital satisfaction between one and three months after the intervention cannot be attributed to increased gestational age since in the control group, the level of marital satisfaction three months later had no significant difference with either the arrival time or a month later.

Another finding of the study suggested that the training program of communication skills is associated with the improved psychological health of pregnant women so that the level of depression in the intervention group fell following the communication skills promotion. This finding reflects that programs designed to increase communication skills can reduce the level of depression in women lacking a good marital quality.

Table 4 The Correlation between marital satisfaction, depression and anxiety before and one month and three months after the intervention

\begin{tabular}{|c|c|c|c|c|c|c|c|c|c|}
\hline & 1 & 2 & 3 & 4 & 5 & 6 & 7 & 8 & 9 \\
\hline 1-Anxiety At Intake & - & & & & & & & & \\
\hline 2-Depression At Intake & $.45^{* *}$ & - & & & & & & & \\
\hline 3-Marital Satisfaction At Intake & $-.38^{* *}$ & $-.36^{* *}$ & - & & & & & & \\
\hline 4-Anxiety At 2th Section & $.54^{* *}$ & $.35^{*}$ & -.19 & - & & & & & \\
\hline 5- Depression At 2th Section & $.30^{*}$ & $.29^{*}$ & -.14 & $.57^{* *}$ & - & & & & \\
\hline 6- Marital Satisfaction At 2th Section & -.26 & $-.40^{* *}$ & $.72^{* *}$ & $-.32^{*}$ & $-.29^{*}$ & - & & & \\
\hline 7- Anxiety At 3th Section & $.42^{* *}$ & .11 & -.30 & $.50^{* *}$ & .17 & $-.37^{* *}$ & - & & \\
\hline 8- Depression At 3th Section & $.35^{* *}$ & $.78^{* *}$ & -.20 & $.42^{* *}$ & .21 & -.26 & .26 & - & \\
\hline 9- Marital Satisfaction At 3th Section & $-.33^{*}$ & $-.40^{* *}$ & $.64^{* *}$ & $-.38^{* *}$ & -.22 & $.81^{* *}$ & $-.49 * *$ & $-.42^{* *}$ & - \\
\hline
\end{tabular}


Contrary to this finding, the available studies' results have shown that the levels of anxiety and depression in women decrease in the mid-pregnancy [22, 23]. Therefore, the present results show that women with marital dissatisfaction during pregnancy would not experience the decline in the level of depression, but in women who acquire communication skills, the level of depression will decrease.

Another research result, indicating a correlation between the level of marital satisfaction and the level of depression, confirms this explanation. Systematic review studies have also shown that other programs effective in marital satisfaction, such as behavioral program and multimodal cognitive behavioral programs are also associated with reduced levels of anxiety and depression [24]. Assessing the impact of cognitive behavioral therapy intervention on reducing depression during pregnancy and after delivery as well as the results of this study consistently have shown that the development of communication skills has a positive effect on marital satisfaction and improving psychological disorders [25]. Another study also reported that marital relations training in the last trimester of pregnancy is associated with enhanced marital relations and improved mental disorders [26].

The impact of the training program on management of relationships and psychological health of mothers has also been reported with an emphasis on features and changes during the pregnancy, changes in the relations of couples and management of couple's relationships through creating intimacy and empathy as well as strategies to cope with anxiety and depression [27].

Enhancing communication skills, in addition to improving interpersonal relationships, of couples through the promotion of conflict resolution skills may also affect the coping styles of people, and thus, improves the marital satisfaction [14] and psychological health [15].

In addition to the effect of communication skills training program on levels of depression, the effectiveness of this program on reducing anxiety was another finding of this study. The results indicated that simultaneous with decreased levels of depression, the levels of anxiety decreased even more than the depression following the acquisition of communication skills in couples, which suggests that increased intimacy between couples and improved relationships following acquisition of communication skills can also be accompanied with a reduction in anxiety.

The strength of the study was couple focused approach of the intervention; however, if marital satisfaction had been assessed in men, the interaction between the couple's marital satisfaction and pregnant women's mental health would also be detectable. Additionally, the interrelationship between the couples and their behaviors was not assessed, which might limit the prediction of the continuity of the intervention effect. In addition, defined gender roles in different societies may affect couple relationships.
Therefore, the effect of the communication skills training intervention to improve the mental health in pregnant women in different communities should be evaluated.

\section{Conclusion}

The evidence provided that the lack of communication skills may be grounds for reducing the quality of couples' relationships; however, enhancing this quality through communication skills training during pregnancy can lead to enhancing women's psychological health during pregnancy.

\section{Abbreviations \\ G: Group; ns: Not significant; RMANOVA: Repeated measures analysis of variance; SD: Standard deviation; Sig: Significance}

\section{Acknowledgments}

We would like to thank Isfahan University of Medical Sciences for financial support.

\section{Authors' contributions}

ZA: Project development, data collection, manuscript writing. AK: Project development, designing the intervention, data collection supervising, acquisition of analysis, interpretation of data, and editing the manuscript. GK: Designing the intervention, interpretation of data, and editing the manuscript. AE: Interpretation of data and editing the manuscript. All authors read and approved the final manuscript.

\section{Funding}

This study was supported by the Isfahan University of Medical Sciences (Grant number: 394349).

\section{Availability of data and materials}

The datasets used during the current study are available from the corresponding author on reasonable request.

\section{Ethics approval and consent to participate}

All procedures performed in participants were in accordance with the ethical standards of the Isfahan University of Medical Sciences and informed written consent was obtained from all participants.

Consent for publication

Not applicable.

\section{Competing interests}

The authors declare that they have no competing interests.

\section{Author details}

${ }^{1}$ Student Research Committee, Schools of Nursing and Midwifery, Isfahan University of Medical Sciences, Isfahan, Iran. ${ }^{2}$ Nursing and Midwifery Care Research Center, School Of Nursing and Midwifery, Isfahan University of Medical Sciences, Hezarjerib AV, Isfahan, Iran. ${ }^{3}$ Behavioral Sciences Research Center, Isfahan University of Medical Sciences, Isfahan, Iran. ${ }^{4}$ Department of Health Education and Promotion, Isfahan University of Medical Sciences, Isfahan, Iran.

Received: 4 November 2018 Accepted: 4 February 2020 Published online: 10 February 2020

References

1. Doss BD, Rhoades GK, Stanley SM, Markman HJ. The effect of the transition to parenthood on relationship quality: an eight-year prospective study. J Pers Soc Psychol. 2009:96:601-19.

2. Mitnick DM, Heyman RE, Smith Slep AM. Changes in relationship satisfaction across the transition to parenthood: a meta-analysis. J Fam Psychol. 2009;23(6):848-52.

3. Lee AM, Lam SK, Sze Mun Lau SM, Chong CS, Chui HW, Fong DY. Prevalence, course, and risk factors for antenatal anxiety and depression. Obstet Gynecol. 2007:110:1102-12.

4. Field T, Diego M, Hernandez-Reif M, Figueiredo B, Deeds O, Ascencio A, et al. Comorbid depression and anxiety effects on pregnancy and neonatal outcome. Infant Behav Dev. 2010;33:23-9. 
5. Pesonen A-K, Lahti M, Kuusinen T, Tuovinen S, et al. Maternal prenatal positive affect, depressive and anxiety symptoms and birth outcomes: the PREDO study. PLoS One. 2016;11:e0150058.

6. Rejno G, Lundholm C, Oberg S, Lichtenstein P, Larsson H, D'Onofrio B, Larsson K, Saltvedt S, Brew BK, Almqvist C. Maternal anxiety, depression and asthma and adverse pregnancy outcomes - a population based study. Sci Rep. 2019;9:13101.

7. Corti S, Pileri P, Mazzocco MI, Mando C, Moscatiello AF, Cattaneo D, Cheli S, Baldelli S, Pogliani L, Clementi E, Cetin I. Neonatal outcomes in maternal depression in relation to intrauterine drug exposure. Front Pediatr. 2019;7:309.

8. Milgrom J, Gemmill AW, Bilszta JL, Hayes B, Barnett B, Brooks J, et al. Antenatal risk factors for postnatal depression: a large prospective study. J Affect Disord. 2008;108:147-57.

9. Hazell Raine K, Nath S, Howard LM, Cockshaw W, Boyce P, Sawyer E, Thorpe K. Associations between prenatal maternal mental health indices and mother-infant relationship quality 6 to 18 months' postpartum: A systematic review. Infant Ment Health J. 2019. Ahead of print.

10. Kang CM. Effects of psychological intervention and relevant influence factors on pregnant women undergoing interventional prenatal diagnosis. J Chin Med Assoc. 2019; [Ahead of print].

11. Yasuma N, Narita Z, Sasaki N, Obikane E, Sekiya J, Inagawa T, et al. Psychological intervention for universal prevention of antenatal and postnatal depression among pregnant women: protocol for a systematic review and meta-analysis. Syst Rev. 2019:8:297.

12. San Lazaro Campillo I, Meaney S, McNamara K, O'Donoghue K. Psychological and support interventions to reduce levels of stress, anxiety or depression on women's subsequent pregnancy with a history of miscarriage: an empty systematic review. BMJ Open. 2017;7:e017802.

13. Askari M, Noah SBM, Hassan SAB, Baba MB. Comparison of the effects of communication and conflict resolution skills training on mental health. Int J Psychol Stud. 2013;5:91.

14. Hargie O. The handbook of communication skills. Third edition ed: Psychology Press; 2006. published 2006. New York: Routledge; 2006

15. Sherod Miller PM, Nunnally EW, Wackman DB. Talking and listening together: couple communication one. Tehran: Roshd; 2013. p. 164

16. Kelson J, Rollin A, Ridout B, Campbell A. Internet-delivered acceptance and commitment therapy for anxiety treatment: systematic review. J Med Internet Res. 2019;21:e12530.

17. Fowers B, Olson DH. Enrich marital inventory: a discriminant validity and cross-validation assesment. J Marital Fam Ther. 1989;15:65-79.

18. Goldberg DP, Gater R, Sartorius N, Ustun TB, Piccinelli M, Gureje O, et al. The validity of two versions of the GHQ in the WHO study of mental illness in general health care. Psychol Med. 1997;27:191-7.

19. Tavakolizadeh J, Nejatian M, Soori A. The effectiveness of communication skills training on marital conflicts and its different aspects in women. Procedia Soc Behav Sci. 2015;171:214-21.

20. Halford WK. Brief therapy for couples: helping partners help themselves. New York: Guilford Press; 2003.

21. Holt-Lunstad J, Birmingham W, Jones BQ. Is there something unique about marriage? The relative impact of marital status, relationship quality, and network social support on ambulatory blood pressure and mental health. Ann Behav Med. 2008;35:239-44.

22. Rallis S, Skouteris H, McCabe M, Milgrom J. A prospective examination of depression, anxiety and stress throughout pregnancy. Women Birth. 2014;27:e36-42.

23. Liou S-R, Wang P, Cheng C-Y. Longitudinal study of perinatal maternal stress, depressive symptoms and anxiety. Midwifery. 2014;30:795-801.

24. Barlow J, Smailagic N, Huband N, Roloff V, Bennett C. Group-based parent training programmes for improving parental psychosocial health. Cochrane Systematic Review - Intervention; 2014. Available at: https://www. cochranelibrary.com/cdsr/doi/10.1002/14651858.CD002020.pub4/full. Accessed Feb 2020.

25. Daley-McCoy C, Rogers M, Slade P. Enhancing relationship functioning during the transition to parenthood: a cluster-randomised controlled trial. Arch Womens Ment Health. 2015;18:681-92.

26. Halford WK, Petch J, Creedy DK. Promoting a positive transition to parenthood: a randomized clinical trial of couple relationship education. Prev Sci. 2010;11:89-100.

27. Milgrom J, Schembri C, Ericksen J, Ross J, Gemmill AW. Towards parenthood: an antenatal intervention to reduce depression, anxiety and parenting difficulties. J Affect Disord. 2011;130:385-94.

\section{Publisher's Note}

Springer Nature remains neutral with regard to jurisdictional claims in published maps and institutional affiliations.

\section{Ready to submit your research? Choose BMC and benefit from:}

- fast, convenient online submission

- thorough peer review by experienced researchers in your field

- rapid publication on acceptance

- support for research data, including large and complex data types

- gold Open Access which fosters wider collaboration and increased citations

- maximum visibility for your research: over $100 \mathrm{M}$ website views per year

At $\mathrm{BMC}$, research is always in progress.

Learn more biomedcentral.com/submissions 